\title{
La derecha chilena y el Estado. El caso del Plan de Acceso Universal de Garantías Explícitas, AUGE
}

\author{
The Chilean right and the State. The case of the Universal Access Plan for Explicit \\ Guarantees, AUGE
}

Carlos Miranda Rozas*

Resumen: En este trabajo se revisan las posiciones asumidas por la derecha política chilena, frente al proyecto de reforma de la salud de 2002, como una forma de aproximarnos a las posturas de este sector político en relación con el rol del Estado en los ámbitos económico y social. Dicha revisión permite advertir que para los diputados de la derecha chilena, el rol asignado al Estado debe subordinarse al objetivo de mantener intocables ciertos rasgos del modelo económico y social heredado de la dictadura, aunque ello implique apoyar medidas contradictorias con el discurso "oficial" de sus partidos, caracterizado, a grandes rasgos, por una condena de la intervención económica y social del Estado y una visión subsidiaria, centrada en la focalización de la política social en los sectores más vulnerables ${ }^{1}$.

Palabras clave: Derecha, plan AUGE, ISAPRES, Neoliberalismo, subsidiariedad.

\begin{abstract}
In this paper, the positions assumed by the Chilean political right are reviewed, respect to the 2002 health reform project, as a way of approaching the positions of this political sector in relation to the role of the State in the economic and social fields. This review allows to warn that for the deputies of the Chilean right, the role assigned to the State must be subordinated to the objective of maintaining untouchable certain features of the economic and social model inherited from the dictatorship, even if it implies supporting contradictory measures with the "official" discourse of its parties, characterized, in broad
\end{abstract}

\footnotetext{
${ }^{*}$ Chileno; Sociólogo y magister en historia. Candidato a Doctor en Historia de la Pontificia Universidad Católica de Valparaíso. cjmirandar@gmail.com.

1 Cabe consignar que el neoliberalismo no es un único conjunto coherente de principios teóricos y engloba a más de una escuela, por lo que acá la expresión la utilizaremos para referirnos, principalmente, a las ideas de la escuela de Chicago, que tuvo una particular influencia en la derecha chilena. También consideramos oportuno consignar que la discusión sobre el giro neoliberal ha sido abordada ampliamente. Entre otros cabe mencionar a Garretón, M. Neoliberalismo corregido; Editorial ARCIS-CLACSO-PROSPAL, Santiago, 2012; Taylor, M. From Pinochet to the third way. Pluto Press, London, 2006; el trabajo colectivo de Saad-Filho, A y Johnston, D. (Comp.). Neoliberalism. A critical reader. Pluto Press, Londres, 2005; Harvey, D. Breve historia del neoliberalismo. Ed. Akal, S.A. Madrid, 2007. Dada esta abundancia de estudios no se consideró necesario volver a presentar la discusión sobre el neoliberalismo.
} 
strokes, by a condemnation of the economic and social intervention of the State and a subsidiary vision, focused on the targeting of social policy in the most vulnerable sectors.

Keywords: Right, AUGE plan, ISAPRES, Neoliberalism, subsidiarity

Recibido: 9 mayo 2019 Aceptado: 22 agosto 2019

\section{Introducción}

La derecha chilena, no ha concitado el mismo interés investigativo que la izquierda, aunque dicho déficit ha tendido a subsanarse en los últimos años. En este trabajo buscamos aportar a la investigación sobre la derecha intentando mostrar que durante los gobiernos de la concertación la derecha chilena, en su práctica parlamentaria, buscó, permanentemente, defender los intereses del empresariado ligado a la salud, aunque ello implicara un alejamiento con ciertos aspectos de la ortodoxia neoliberal respecto de la acción económica y social del Estado.

Para caracterizar a la derecha, partimos de la base de que dicho concepto no posee un contenido sociológico abstracto, sino que es un concepto histórico, puesto que su contenido varía con el tiempo. En este sentido Sofía Correa es clara en señalar que las nociones de izquierda y derecha no son absolutas, "sino que varían históricamente; son conceptos cuyo significado es relativo al momento histórico de que se trate... (y por lo mismo) pueden designar diferentes contenidos según los tiempos y situaciones" 2 .

En función de lo anterior, consideramos que el rasgo distintivo más general de la derecha chilena es su defensa de la propiedad privada frente a las amenazas redistributivas de otros sectores políticos y sociales y, en función de ello, ha desplegado diversas estrategias y asumido distintas visiones teóricas, pero desde fines de la década de 1970 el neoliberalismo comenzó a ser la teoría hegemónica de este sector político3, puesto que otorgaba un sustento teórico al proyecto de destruir la capacidad de los trabajadores y otros sectores políticos y sociales de amenazar la propiedad y la ganancia privada. Así, esta teoría que promovía un desentendimiento del Estado y una exacerbación de la eficacia de los mercados, contribuyó a la eliminación de todas las formas de intervención estatal que beneficiaban a los trabajadores, de tal modo, que los sectores propietarios aumentaron significativamente su participación en la distribución de los ingresos ${ }^{4}$.

Esta adopción del paradigma neoliberal, sobre todo en su versión de la escuela de Chicago, implicó una particular visión sobre el rol del Estado en materia económica y social,

2 Corra, Correa, S. Con las riendas del poder. La derecha chilena en el siglo XX. Santiago. Ed. Sudamericana. 2004, 20.

3. Correa. Óp. cit. 265 y $270-272$.

${ }^{4}$ Dicha reversión de los ingresos se muestra con claridad en Piketty, T. El capital en el siglo XXI. México, FCE, 2015. 
la que se expresa con el concepto de Estado subsidiario, que, en su acepción neoliberal, se refiere a que el accionar del Estado debe ser funcional al mercado, no asumiendo funciones que por su naturaleza le corresponden a los particulares y acotando su intervención a acciones que permitan el funcionamiento mercantil eficiente e interviniendo, solamente, cuando los agentes del mercado no puedan o no deseen actuar ${ }^{5}$. Estas ideas impregnaron toda la visión de la derecha respecto del rol del Estado en lo económico y social, lo que puede evidenciarse, por ejemplo, en la declaración de principios de la UDI cuando señala que dicho partido:

...postula el principio de subsidiariedad como base de la sociedad libre. El respeto a la libertad personal y a la autonomía de los cuerpos sociales intermedios exige que ni el Estado, ni ningún otro organismo de la sociedad invadan o absorban el campo específico de las entidades menores o el ámbito de la libertad de cada persona.

Por vía subsidiaria, corresponde al Estado, además, asumir aquellas actividades necesarias o claramente convenientes para el país que, siendo propias del ámbito de los particulares, en la práctica no puedan ser cubiertas por éstos ${ }^{6}$.

Asimismo, en los objetivos de RN se puede leer lo siguiente: “El resguardo del bien común exige respetar el principio de subsidiariedad. Desde la perspectiva del individuo, este principio resguarda la libre iniciativa personal y, desde la perspectiva del Estado, se traduce en la limitación de su campo de acción a aquellas tareas que no pueden ser asumidas por las personas o sus grupos intermedios" 7 .

Lo anterior conlleva una visión negativa de la intervención estatal en el plano económico, pero también en el ámbito social. Dicha visión está en sintonía con las ideas de Friedman quien afirmaba que el gasto social es fuente de múltiples problemas económicos, porque obliga a aumentar el ingreso fiscal para financiar los programas sociales, lo que se traduce en más emisión monetaria y más impuestos, lo que acarrea, inevitablemente un aumento de la inflación, pero además la política social, no garantiza que las personas accedan a ciertos beneficios o que estos sean de mejor calidad. Esta idea, Friedman la ilustra con un ejemplo del ámbito de la salud:

... convertir una cosa en una obligación gubernamental no mejora necesariamente a esa cosa. La medicina socializada ha sido probada en muchos países y, generalmente, ha llevado a una reducción de la calidad del cuidado médico y no a una mejora del mismo.

... Como ustedes saben, hasta 1920, Gran Bretaña era una sociedad completamente de "laissez faire". Los hospitales y los cuidados médicos se ofrecían privadamente. En los últimos 50 años Gran Bretaña se ha transformado en un país socializante; y luego de la segunda guerra mundial adoptó un sistema completo de medicina socializada.

\footnotetext{
5 Bohoslavsky, E. “¿Qué es lo nuevo de la nueva derecha en Chile? Anticomunismo, corporativismo y neoliberalismo, 1964-1973”. História Unisinos. Vol. 16, n 1, 2012. pp. 5-14.

http://revistas.unisinos.br/index.php/historia/article/view/htu.2012.161.01.

${ }_{6}$ Declaración de Principios Unión demócrata Independiente (UDI). Disponible en:

http://www.udisantiago.cl/documentos/dec_princip.pdf

7 Objetivos de Renovación Nacional para un Desarrollo Integral. En Allamand. La centroderecha del futuro.

Editorial Los Andes. Santiago, 1993, p 121.
} 
Una de las razones por las cuales lo adoptó, fue porque se suponía que las facilidades hospitalarias eran inadecuadas.

Actualmente, después de más de 25 años de medicina socializada, más de los dos tercios de las camas hospitalarias se encuentran en hospitales construidos antes de 1900 y que fueron construidos en la "era" de la medicina de la empresa privada iy no en la era de la medicina socializada! ${ }^{8}$

Como se puede apreciar, se plantea que la política social no resuelve los problemas de las personas y estos pueden ser abordados de mejor manera si son asumidos por agentes privados, ya que estos entregaran una mayor cantidad de servicios y de mejor calidad. Además, la política social no solo genera presiones inflacionarias, déficits presupuestarios y es ineficiente, sino que, además, tiene efectos perjudiciales en el ámbito moral, ya que desincentiva el esfuerzo personal. En este sentido la lucha contra la pobreza fracasó porque disuadió a los pobres de tratar de progresar, de buscar trabajo, de protegerse de las enfermedades, de cuidar a sus hijos, etc., lo que, a su vez, generó "el mantenimiento de los individuos en categorías desvalorizadas, la pérdida de dignidad y de autoestima y la homogeneización de la clase pobre" ${ }^{9}$, lo que también se traducen en problemas económicos, ya que "mina la base misma del sistema capitalista que se basa en incentivos diferenciales por el mérito y el esfuerzo"10.11

8 Friedman, M. “Bases para un desarrollo económico". Conferencia ofrecida por el Dr. Milton Friedman en el Edificio Diego Portales de Santiago, el 26 de marzo de 1975. En Soto, A (comp). Un legado de libertad. Milton Friedman en Chile. Instituto Democracia y Mercado/Atlas Economic Research Foundation/ Fundación para el Progreso. Santiago, 2012. pp. 56 - 57.

${ }_{9}^{9}$ Laval y Dardot. La Nueva Razón del Mundo. Barcelona. Gedisa, 2013. p 212.

10 Morresi, S. La nueva derecha argentina, la democracia sin política. Universidad Nacional General SarmientoBiblioteca Nacional, Buenos Aires, 2008. p 24. Pese a esta visión negativa de la política social, es importante recalcar que el neoliberalismo, de todas formas, posee una dimensión social desarrollada a partir de la idea general de la no intervención estatal y subsidiariedad y cuya máxima fundamental es lograr la eficacia y eficiencia en el gasto público a través de la focalización del mismo, solo en los sectores más pobres. Taylor estudia como durante la dictadura chilena se reformaron las políticas sociales para adoptarlas a dichas ideas. Taylor, óp. cit. pp. 77 - 99. Por otra parte, en lo que concierne al plano de la salud el informe del Banco Mundial de 1993, plasma de manera explícita las ideas de focalización, eficiencia y subsidiariedad en salud, cuando plantea que los gobiernos debían centrarse en la atención de los sectores más pobres, en "corregir" las deficiencias del mercado y en buscar la eficacia en la relación entre costos y beneficios. Todo ello requería que los gobiernos se preocuparan por: 1) propiciar que las familias mejoraran su salud mediante medidas pro crecimiento económico y aumento de la inversión en educación; 2) focalizar adecuadamente el gasto público, reduciéndolo en establecimientos terciarios y formación de especialistas y centrándose en los servicios clínicos esenciales (inmunización, atención durante el embarazo, enfermedades comunes en la niñez, etc.), así como también, promoviendo conductas que reduzcan los riesgos (campañas contra el SIDA, la conducción sin alcohol, reducción del consumo de tabaco, etc.); y 3) promover la diversidad y la competencia en la esfera de las prestaciones y los seguros de salud, alentando la participación privada para cubrir los servicios no incluidos en el mínimo esencial. Banco Mundial. Informe sobre el desarrollo Mundial 1993. Invertir en salud. pp. 4 - 11.

http://documentos.bancomundial.org/curated/es/282171468174893388/Informe-sobre-el-desarrollomundial-1993-investir-en-salud.

Como veremos en el desarrollo del trabajo, la derecha también entrará en contradicciones con algunos de estos lineamientos.

11 *** Nota explicativa de cambios. Se debe eliminar de versión definitiva. Estos párrafos se agregaron para reforzar la idea de que los autores neoliberales, ligados a la escuela de Chicago posee una visión general negativa 
Sin embargo, una vez que pasó el "peligro socialista", la derecha ya no necesitaba recurrir a la demonización del Estado para defender los intereses del empresariado, por lo que, una vez recuperada la democracia, la derecha fue capaz de mostrar pragmatismo y flexibilidad, para hacer frente a los proyectos de reforma emanados de los gobiernos de la Concertación, lo que implicó matizar y enriquecer sus visiones respecto del rol del Estado en los ámbitos económico y social, tal como se refleja en las posturas manifestadas por los diputados de la derecha a propósito de la discusión en torno al proyecto de "Acceso Universal de Garantías explícitas en Salud", conocido como AUGE.

Para alcanzar los objetivos del presente trabajo se analizó toda la discusión en la Cámara de Diputados del proyecto en cuestión, focalizando el análisis en las intervenciones de los diputados de Renovación Nacional y la UDI, realizadas en las comisiones de salud y hacienda, así como sus discursos en la sala de la Cámara de Diputados ${ }^{12}$.

La fuente de donde se obtuvo la información fue la "Historia de la Ley N N $^{0}$ 19.966. Establece un régimen de garantías de salud". Disponible en:

https://www.bcn.cl/historiadelaley/nc/historia-de-la-ley/5682/

\section{La posición de la Derecha frente al proyecto de reforma ${ }^{1314}$.}

\subsection{Primera parte del debate: mensaje presidencial y la discusión en las comisiones de hacienda y salud.}

El proyecto de ley de Acceso Universal de Garantías Explícitas de Salud (AUGE) fue ingresado a la Cámara de Diputados el 22 de mayo de 2002. En el mensaje presidencial se señalaba que el proyecto de reforma estaba animado por los principios de derecho a la salud,

de la política social, sin perjuicio de que esas ideas negativas intentaron plasmarse en una política social concreta afín a dichas ideas, tal como se señala en la cita precedente.

$12 * * *$ Nota explicativa. Se debe eliminar de versión definitiva: los evaluadores sugieren especificar metodología, pero no utilicé ninguna metodología de análisis de textos en particular (análisis estructural, de contenido, u otro) y simplemente intenté identificar, en las intervenciones de los diputados de la derecha, las ideas planteadas cada vez que se hacía referencia al Estado y ver si esas ideas estaban o no en sintonía con el paradigma neoliberal en su versión de la escuela de Chicago. También busqué identificar los argumentos utilizados para defender a las isapre. En función de ello no me es posible plantear explícitamente una metodología en particular.

13 *** Nota explicativa de cambios. Se debe eliminar de versión definitiva. En este apartado se mantuvieron solo los párrafos en los que se mostraba un alejamiento de los principios neoliberales de no intervención estatal, subsidiariedad y focalización en los más pobres. Es decir, aquellos párrafos que muestran que la derecha era partidaria de una complementariedad público privada que invertía el principio de subsidiariedad y aseguraba ganancias a los más ricos y aquellos párrafos en que se muestra que la derecha se negaba a tocar los intereses de las empresas ligadas a la salud.

$14 * * *$ Nota explicativa de cambios. Se debe eliminar de versión definitiva. Acogiendo la sugerencia de incorporar sub títulos, opté por organizar el apartado en términos temporales, es decir, presentar la discusión en cada una de las diferentes fases del debate parlamentario, aunque resulte, en parte, repetitivo. Ello para resaltar que la derecha volvía reiteradamente sobre los mismos tópicos 
equidad en salud, solidaridad, eficiencia y participación social, todos los cuales permitirían mejorar sustancialmente las condiciones de salud de la población ${ }^{15}$.

Entre los elementos, contenidos en el mensaje, consideramos relevante destacar que se trata de unas garantías universales, que estarían focalizadas en las enfermedades de mayor impacto, costo, etc., pero sin discriminación por nivel socioeconómico. Otro elemento interesante se relaciona con que la idea de solidaridad debe extenderse al sector privado, ya que se establece que las Instituciones de Salud Previsional (ISAPRE) otorguen las garantías, sin discriminación de precios, a todos sus beneficiarios. Esto permitirá desvincular el costo de los seguros, del riesgo individual de enfermar ${ }^{16}$

También en relación con el principio de solidaridad, la reforma preveía la creación de un Fondo de Compensación Solidario, que se conformaría con aportes de las cotizaciones de los cotizantes de ambos sistemas de salud. Este fondo tendría por objetivo contribuir al financiamiento del régimen de garantías. Es de destacar que no se propusieron reformas para subsanar lo que diversos estudios señalan como la principal fuente de inequidad en el sistema de salud, esto es, la existencia de dos seguros de salud, uno privado y otro público, lo que asegura buenas prestaciones de salud, preferentemente a los usuarios de los seguros privados. En este sentido la derecha no tendría que enfrentarse a propuestas de cambio sustanciales al modelo, por lo que mostró, inicialmente, una disposición positiva al proyecto en general, aunque, como veremos, lo cuestionará en algunos puntos fundamentales.

En su primer trámite constitucional el proyecto fue discutido por la Comisión de Salud, en 19 sesiones, entre los días 18 de junio de 2002 y 13 de noviembre del mismo año. Dicha comisión estaba conformada por 13 diputados, de los cuales 6 pertenecía a la alianza de derecha (4 UDI y 2 RN) ${ }^{17}$, es decir no poseían la mayoría en la comisión. Es de considerar que el proyecto fue aprobado en general por la unanimidad de los miembros de la comisión, lo que implica, que en principio la derecha, se abrió a la discusión de un proyecto, que incluía elementos de universalidad y solidaridad y que tocaba las cotizaciones de los usuarios de la ISAPRE, aunque, como veremos, durante la tramitación del proyecto intentará defender, en todo momento, los intereses del empresariado ligado a la salud. ${ }^{18}$

En esta primera instancia de discusión la derecha presentó solo tres indicaciones, dos de las cuales se referían a aspectos que podríamos llamar formales y solo una por un tema de fondo. Dicha indicación (presentada por todos lo disputados de derecha presentes en la comisión) consistía en incorporar un nuevo artículo 14 el que decía lo siguiente:

\footnotetext{
15 Mensaje Presidencial a la Cámara de Diputados. Historia de la Ley No 19.966. "Establece un régimen de garantías de salud". Congreso Nacional de Chile, 2004. 8- 12.

https://www.bcn.cl/historiadelaley/nc/historia-de-la-ley/5682/

16 Congreso Nacional. Óp.cit. 16.

17 En concreto los diputados que conformaban la comisión de salud en 2002 eran los siguientes: Cornejo, Patricio (DC),Cristi, María Angélica (UDI), Accorsi, Enrique (PPD), Aguiló, Sergio (PS), Bayo, Francisco (RN), Forni, Marcelo (UDI), Girardi, Guido (PPD), Masferrer, Juan (UDI), Melero, Patricio (UDI), Ojeda, Sergio (DC), Olivares, Carlos (DC), Palma, Osvaldo (RN) y Robles Alberto (PRSD). $1^{\circ}$ informe Comisión Salud. Congreso Nacional. 190.

$18 * * *$ Nota explicativa de cambios. Se debe eliminar de versión definitiva. Acá se introdujo algunas modificaciones, acogiendo lo señalado por los evaluadores cuando afirman que: "es un hecho que la derecha finalmente se negó a todas esas medidas o quedaron aprobadas de tal manera definidas, que no cumplieron los objetivos explicitados en un comienzo". Afirmaciones con las que tengo pleno acuerdo.
} 
Cada vez que un beneficiario del Fondo Nacional de Salud requiera una prestación que forme parte del Régimen de Garantías en Salud, recibirá un documento emitido por aquél en que constará la prestación solicitada, el monto del copago que corresponda hacer al beneficiario y el plazo dentro del cual aquélla le deberá ser otorgada en la Red Nacional del Sistema Público conforme a lo establecido en el Régimen...

En caso de que el plazo indicado en el inciso primero expire sin que la respectiva prestación haya sido otorgada, no obstante haber sido solicitada por el beneficiario, éste podrá concurrir a cualquier profesional o establecimiento que tenga convenio con el Fondo Nacional de Salud...

Si el copago que deba realizar el beneficiario, de acuerdo con lo indicado en el inciso precedente, fuese inferior al que correspondería hacer, conforme al convenio celebrado entre el profesional o establecimiento de salud respectivo y el Fondo Nacional de Salud, la diferencia será de cargo de éste, y deberá ser enterada al profesional o establecimiento de salud ante la sola presentación del documento, el que tendrá, para todos los efectos legales, el carácter de título ejecutivo en contra del Fondo Nacional de Salud ${ }^{19}$.

La diputada Cristi fundamentó la indicación, argumentando que era necesario asegurar el cumplimiento de las garantías, lo que obligaba, no solo a expresarlas en la ley, sino que también había que establecer los medios para su cumplimiento, por lo que de no otorgarse la prestación en la red pública, ésta debía ser otorgada por un prestador privado 20. Por su parte el diputado Melero, coautor de la iniciativa, señaló que la indicación buscaba evitar que el Estado se viera enfrentado a una gran cantidad de demandas judiciales por el posible incumplimiento de las garantías (dado que ya se veía en problemas de atender a sus beneficiarios) y, por otra parte, se deseaba explicitar la obligación del Estado respecto del cumplimiento de las garantías en forma expedita ${ }^{21}$.

Esta indicación, por contener disposiciones relativas a nuevos gastos del Estado, facultad privativa del ejecutivo, fue declarada inadmisible por el presidente de la comisión, Patricio Cornejo, pero será respuesta con modificaciones de manera insistente por los parlamentarios de derecha a lo largo de todo el debate parlamentario. Por ello creemos que vale la pena detenerse en su análisis.

En primer lugar la Derecha aparece apoyando un elemento de universalidad en la provisión, por parte del Estado, de un servicio o derecho social, lo que está a contrapelo con las ideas neoliberales respecto de que la universalidad en la prestación de servicios es perjudicial, porque desincentiva el esfuerzo individual ${ }^{22}$, porque resulta ineficiente en términos económicos y porque se constituye en un subsidio a los grupos de ingresos altos ${ }^{23}$.

19 Congreso Nacional, óp. cit. p 119.

${ }^{20}$ María Angélica Cristi. Congreso Nacional, óp. cit. 119

21 Patricio Melero. Congreso Nacional, óp. cit. p 119.

${ }^{22}$ En este sentido para los defensores del neoliberalismo, se debe privilegiar y estimular el esfuerzo individual y la ayuda social debe reservarse, sólo para aquellos que "no pueden por si solos", puesto que, de generalizarse, se desincentivaría el trabajo. Al respecto Tony Judt señala que para Bill Clinton o Margaret Thatcher "sería un disparate hacer universales los beneficios del bienestar para todos los que los necesitan. Si los trabajadores no están desesperados, ¿por qué van a trabajar?". Judt, T. Algo va mal. Madrid. Taurus, 2010, 21.

${ }_{23}$ Y contradiciendo también las sugerencias del Banco Mundial, ya que, en su informe de 1993, plantea que el problema principal del financiamiento público universal es que "subvenciona a personas acomodadas, que 
Por lo mismo consideramos que en este punto, la Derecha no se apega al pie de la letra al paradigma neoliberal ${ }^{24}$. Sin embargo, creemos que lo más significativo de la indicación es que muestra una particular visión sobre la relación público - privada, ello porque, de alguna forma, se invierte el principio de subsidiariedad, que dice que en aquellas esferas donde el mercado no pueda (o no quiera) operar entonces solo ahí debe actuar el Estado. Aquí por el contrario se afirma que cuando el Estado, en su rol subsidiario, no pueda prestar un servicio a quienes no pueden pagar por él, entonces se debe recurrir al mercado, pero no a través de una mercantilización "convencional", sino a través de una mercantilización con subsidios estatales, lo que permite asegurar el disfrute de la prestación privada a quienes no tienen los ingresos necesarios para pagarla y, también se asegura que los prestadores privados, puedan lucrar con fondos públicos, lo que implica un subsidio a la ganancia privada.

Acá es preciso destacar que la dicotomía Estado - mercado, como dicotomía de suma cero, que algunos creen lo propio del neoliberalismo (que opta por el mercado) y del socialismo (que opta por el estado) es totalmente negada, ya que se habla de una complementariedad Estado - mercado.

De lo anterior se desprende que la Derecha no es partidaria de una mercantilización total, ni siquiera de una separación entre sistemas privados y sistemas públicos, sino que se muestra partidaria de una "mercantilización subsidiada" que le asegura a los privados un buen negocio, atendiendo a personas que por sus bajos recursos no habrían podido atenderse por sí solas en el sector privado, con lo que el Estado crea un negocio rentable, ahí donde no lo había. ${ }^{25}$

Otro elemento central del proyecto se refería a la creación de un Fondo de Compensación Solidario, cuya justificación, objetivos e impacto fueron aclarados por Marcelo Tockman, a la fecha, jefe del Departamento de Estudios de la Dirección de Presupuestos del Ministerio de Hacienda. Según Tockman este Fondo debía contribuir a otorgar elementos de equidad y solidaridad en el sistema y servir como incentivo para que las ISAPRE, no dieran un trato discriminatorio a las personas de mayores riesgos. Al respecto señaló:

La situación actual es que las Isapres discriminan a los enfermos crónicos, mujeres en edad fértil y personas de la tercera edad, y a cualquier individuo en que la Isapre pueda identificar a priori que el costo esperado de atenderlo es mayor que el costo promedio...

pueden permitirse pagar sus propios servicios, y con ello se reducen los recursos públicos disponibles para los pobres". Banco Mundial, óp. cit. p 12.

$24 * * *$ Nota explicativa de cambios. Se debe eliminar de versión definitiva. En la evaluación se plantea, que aquí la derecha no está aceptando una idea de universalidad, sino que está apoyando un subsidio focalizado. Sin embargo, según nuestra interpretación, la derecha está proponiendo un subsidio para cualquier usuario de FONASA que no fuera atendido en el tiempo establecido, no solamente para los usuarios de escasos recursos. Es decir, la derecha, no está proponiendo que solo los más pobres puedan recurrir a prestadores privados si el sistema público no puede asegurar la prestación en el tiempo establecido, sino que cualquier usuario, por lo que, consideramos que la derecha, en este punto no se está ateniendo a la idea de focalización. Por todo ello decidí dejar sin alteraciones todo el párrafo.

25 *** Nota explicativa de cambios. Eliminar de versión final. Acá se eliminaron 4 párrafos referentes a las limitaciones impuestas a las ISAPRES. Ello porque estoy de acuerdo con la corrección hecha por el evaluador y porque estimé que los párrafos citados no contribuían a reforzar la idea central del trabajo. 
Lo que hace la Isapre con estas personas es fijar precios mayores que el promedio, efectúa adecuaciones más onerosas que el promedio o, derechamente, rechaza la afiliación ${ }^{26}$.

En función de lo anterior continúa su exposición señalando que el primer objetivo del Fondo de Compensación Solidario sería:

Reducir los incentivos a la discriminación por riesgo que tienen las Isapres. Esto se logra pagando a los seguros los gastos esperados de cada tipo de beneficiario, de manera que les sea indiferente asegurar a personas de alto o bajo riesgo. Es decir, una Isapre estaría dispuesta a recibir a una mujer en edad fértil en la medida en que la mujer esté dispuesta a pagar el mayor costo esperado o en que éste sea compensado, y eso es lo que hará el Fondo de Compensación... cuando la Isapre afilie a una mujer en edad fértil, va a recibir una compensación, esto es, un pago adicional por parte del Fondo de Compensación... La Isapre ya no tendrá necesidad de excluirla ${ }^{27}$.

Además agregó que otro de los objetivos del Fondo sería aumentar la solidaridad entre sanos y enfermos y entre personas de mayores ingresos con los de menores ingresos, ya que los recursos se distribuirían entre toda la población y no solo entre los afiliados a una misma ISAPRE28. Por último, señaló que el Fondo tenía como objetivo compensar a FONASA, puesto que dicha institución afiliaba, sin discriminar, a las personas, que por sus riesgos, poseían un gasto esperado en salud, mayor que el promedio 29 .

En lo referente a como se iba a conformar el Fondo, el proyecto señalaba que tanto FONASA, como las ISAPRE, deberían contribuir con un monto fijo por cada afiliado, denominado Prima Universal, sin la posibilidad de aumentar la cotización legal del 7\%. Dicha Prima sería determinada periódicamente de acuerdo a la cantidad de enfermedades incorporadas en las garantías y considerando las variables de sexo y edad.

El Fondo sería administrado por el Ministerio de Salud y lo redistribuiría según el uso que cada entidad hiciera de las Garantías Explícitas, lo que implicaba que las ISAPRE, contribuirían en un monto mayor que el que recibirían, puesto que FONASA tiene como beneficiaria a una población con mayor riesgo ${ }^{30}$.

En este punto del debate, los diputados de la Concertación, Accorsi, Aguiló, Ojeda, Robles y Rossi presentaron indicaciones que establecían que el Fondo solo debía operar entre las propias ISAPRE, porque la solidaridad ya existía en FONASA y porque podía conllevar un traspaso de recursos del ente público a las instituciones privadas, si es que estas asumían usuarios de mayor riesgo. Ante ello la discusión se produjo, principalmente entre el ejecutivo y los diputados antes señalados. De este modo la Derecha fue un espectador en el debate y, aunque rechazó los artículos con las indicaciones presentadas (las que, sin

${ }^{26}$ Marcelo Tockman. Congreso Nacional. Óp. cit. 153.

27 Marcelo Tockman. Congreso Nacional. Óp. cit. 154

${ }_{28}$ Marcelo Tockman. Congreso Nacional. Óp. cit. 155.

${ }^{29}$ Marcelo Tockman. Congreso Nacional. Óp. cit.155

30Marcelo Tockman. Congreso Nacional. Óp. cit. 155. 
embargo se aprobaron con los votos de la Concertación), no presentó, por su parte, ninguna indicación, ni tampoco propuso rechazar el Fondo de plano ${ }^{31}$.

En esta primera etapa la Derecha no asumió la virulencia con la que atacaría después el Fondo, lo que se produjo, a nuestro juicio porque la aprobación de las indicaciones presentadas por los diputados del pacto gobernante, le quitaron el potencial redistributivo al Fondo, al limitarlo a compensar los riesgos y costos entre las ISAPRES, pero eliminando la posibilidad de que los recursos administrados por dichas empresas, contribuyeran a financiar el uso de las Garantías por parte de los beneficiarios de FONASA.

El último punto del debate, en esta primera instancia se refiere a la creación de un Fondo Maternal Solidario, que reemplazaría al subsidio estatal maternal vigente, ya que éste se dirigía en gran medida a mujeres pertenecientes a los dos quintiles de mayores ingresos ${ }^{32}$ y los aportes eran en un $100 \%$ estatales. Por ello se proponía crear un fondo conformado por el $0,6 \%$ de la cotización de los usuarios de ambos sistemas, con lo que se introduciría un componente de solidaridad entre hombres y mujeres y entre personas de mayores y menores ingresos. Puesta en votación, la propuesta fue rechazada por la Derecha (aunque aprobada con los votos concertacionistas), pero no hubo discusión de la misma, con lo que no podemos conocer en esta etapa las razones de tal rechazo, aunque ellas se explicitarán en el siguiente trámite en la Comisión de Hacienda. Con todo, el proyecto fue aprobado en general por la unanimidad de los parlamentarios presentes en la Comisión de Salud y por lo tanto este pasó, en su segundo trámite, a ser revisado por la Comisión de Hacienda de la Cámara de Diputados.

Dicha comisión se reunió solo una vez el día 3 de diciembre de 2002 y estaba conformada por trece diputados, de los cuales 7 pertenecía a la coalición de gobierno y 6 a la alianza de derecha ${ }^{33}$. En el seno de esta comisión el debate se instauró, fundamentalmente, en torno a los artículos relativos al financiamiento del Fondo Maternal Solidario, que reemplazaría los subsidios estatales en esta materia, pero la propuesta de creación del Fondo fue aprobada por unanimidad. Ante esta propuesta el diputado UDI, Julio Dittborn, señaló que se estaba creando un verdadero impuesto a las ISAPRE, el que, a su juicio, sería traspasado a los afiliados. Luego anunció que, en su oportunidad, se plantearía la constitucionalidad respecto de esta disposición ${ }^{34}$.

Asimismo la diputada María Angélica Cristi, señaló que la propuesta implicaba "focalizar con fondos privados, puesto que el subsidio será cancelado con los aportes del resto de los cotizantes" 35 . Como se puede apreciar, aquí se plantea por primera vez una defensa de las ISAPRE, ya que la Derecha votó en bloque para rechazar, no el Fondo mismo, sino su modalidad de financiamiento, ya que implicaba tomar recursos que administraban las ISAPRE, para ser redistribuidos entre todas las mujeres que lo requirieran en la etapa del

\footnotetext{
$311^{\circ}$ Informe Comisión de Salud de la Cámara de Diputados, Congreso Nacional. Óp. cit. 156 - 158

$321^{\circ}$ Informe Comisión de Hacienda. Congreso Nacional. Óp. cit. 158

33 Lorenzini, don Pablo (DC), Aguiló, don Sergio (PS), Álvarez, don Rodrigo (UDI), Cardemil, don Alberto (RN), Cristi, señora María Angélica (UDI), Dittborn, don Julio (UDI), Escalona, don Camilo (PS), Hidalgo, don Carlos (RN), Jaramillo, don Enrique (PPD), Ortiz, don José Miguel (DC), Silva, don Exequiel (DC), Tohá, señora Carolina (PPD) y Von Mühlenbrock, don Gastón (UDI). Congreso Nacional. Óp. cit. 201.

34Julio Dittborn. Comisión de Hacienda. Congreso Nacional. Óp. cit. 198.

35 María Angélica Cristi. Comisión de Hacienda. Congreso Nacional. Óp. cit. 200.
} 
pre y postnatal. Ante esta discusión la Derecha de inmediato plantea, lo que será su principal arma cuando considera que se está atacando un punto intransable: la amenaza con recurrir al Tribunal Constitucional, para que evalúe si determinada parte del proyecto se ajusta o no a la carta fundamental. Sin embargo, los artículos en cuestión fueron aprobados gracias a la mayoría de un voto que poseía la alianza de gobierno, con lo que la discusión se trasladó a la Sala de la Cámara de Diputados.

\subsection{Primera discusión en la sala.}

Esta instancia se llevó a cabo el 12 de diciembre de 2002 y en ella el proyecto se aprobó en general, pero se mantuvo el desacuerdo respecto de los puntos señalado. La Derecha, en la voz de Patricio Melero, reiteró su buena disposición hacia el proyecto en general y reconoció que subsanaba algunos de los problemas del sistema de salud vigente en Chile entre los que se encontraba el de la eficiencia en la administración de los recursos. $\mathrm{Al}$ respecto señaló que:

Podemos diagnosticar que muchos recursos no han llegado a los usuarios..., que la utilización y la transparencia de los recursos asignados no han sido las adecuadas, y que se ha trabajado básicamente con la premisa de los presupuestos históricos, sin revisar esas cifras en el tiempo y sin aplicar medidas de gestión y de administración más eficientes para aumentar y mejorar la productividad por cada peso que se invierte en el sector salud.

Es más, las cifras demuestran que, en vez de crecer la productividad en salud, tal como se señala en el informe de la Cepal, patrocinado por investigadores del Ministerio de Hacienda, la productividad por peso gastado, en vez de crecer, ha disminuido ${ }^{36}$.

Las ideas de eficiencia y productividad serán recurrentes en la argumentación esgrimida por los parlamentarios de la derecha para criticar, aprobar o rechazar las iniciativas legislativas de los gobiernos de la Concertación, lo que ilustra, con bastante claridad, algunos de los compromisos ideológicos de este sector político, ya que se recurre a dichos conceptos para abordar un tema ${ }^{37}$, considerado por los otros jefes de bancada, no como un producto, sino como un derecho. Sin embargo, se debe dejar en claro que, para la UDI, el tema del acceso a la salud no es un tema secundario, lo que se evidencia en el siguiente extracto del discurso del mismo diputado Melero:

Lo que a la UDI más le agrada de la reforma a la salud, es el concepto de que, por primera vez, tendremos la posibilidad de garantizar a los chilenos, ante un conjunto de enfermedades, que van a ser atendidos en un tiempo acotado y que tendrán una cobertura financiera adecuada

\footnotetext{
36 Patricio Melero, discusión en sala. Congreso Nacional. Óp. cit. 225.

37 La argumentación es muy similar a la señalada por Fridman cuando se refiere a la sanidad en Gran Bretaña: “Por ejemplo, en Gran Bretaña, en ocho años (de 1965 a 1973), el personal médico ocupado aumentó un 28\%, el personal administrativo un 51\%, mientras que la producción (número medio de camas de hospital ocupadas diariamente) se redujo un $11 \%$... y no era por la falta de pacientes, ya que las listas de espera alcanzaban 600.000 personas". Coto, J. Resumen del texto Libertad de elegir de Milton y Rose Friedman. p 15. www.unavisioreformista.wordpress.com.
} 
para enfrentar la garantía de salud que se les va a dar por ley. Eso constituye, sin duda, un paso sustancial, importante, determinante, que cambia el eje de la incertidumbre que hoy tienen muchos chilenos al no saber cuándo van a ser intervenidos ni si van a tener o no las posibilidades de financiar el copago que les genere la intervención o la acción de salud que requirieron ${ }^{38}$.

Como se puede apreciar, hay una valoración de la universalidad en el acceso a la salud, lo que se aleja del principio de subsidiar solo a los más pobres, pero dicha universalidad, debe estar supeditada a los criterios de eficiencia porque, al decir del diputado, "si queremos cubrir y garantizarlo todo, no hay bolsillo que aguante" 39 , por lo que se apoya la idea de que se priorice un conjunto de enfermedades "que representan cerca del 70 por ciento de la demanda de atención de salud" 40 . En este sentido podemos resumir la postura de la Derecha en este tema de la siguiente forma: acceso universal al tratamiento de ciertas enfermedades de alto impacto, sí; acceso universal garantizado a toda prestación en salud, no. En este sentido, la argumentación de Melero, está en completa sintonía con lo propuesto por el Banco Mundial en su informe de $1993^{41}$.

Dicha postura se desprende de las condiciones económicas del país, por lo que Melero y la derecha en general, reiteran de manera persistente que cuando se discute un tema de política social, no solo se está frente a un problema de principios o ético, sino que también se está frente a un problema económico. Esto resulta relevante porque se hace hincapié en que la política social no opera en un marco autónomo, sino que debe ligarse con las condiciones económicas que la hacen posible y debe evitarse que afecte negativamente el funcionamiento económico del país, es decir, derechos sociales y economía, deben ser tratados como un todo. Esto lo señala Melero con claridad en el siguiente párrafo:

Pero quiero rescatar el sistema de prioridad que obviamente, en un país con escasez de recursos, es, a mi juicio, la forma adecuada de enfrentar la realidad, como también lo dicen el sentido común y el buen criterio respecto de muchas cosas en la vida, de que cuando no se puede hacer todo, hay que resolver lo más importante primero y dejar en prioridad secundaria las cosas que no requieren tanta urgencia ${ }^{42}$.

Esta idea está muy a tono con las ideas neoliberales, lo que se evidencia, claramente, cuando se considera, que una de las principales críticas que los teóricos neoliberales realizan al Estado de Bienestar, se refiere, justamente, al impacto económico negativo que tenían las

\footnotetext{
38 Melero, Discusión en sala, Congreso Nacional. Óp. cit. 227

${ }^{39}$ Melero, Discusión en sala, Congreso Nacional. Óp. cit. 228

40 Melero, Discusión en sala, Congreso Nacional. Óp. cit. 228.

41 En dicho informe se señala de manera explícita que uno de los problemas de los sistemas de salud, es la asignación equivocada de recursos. Al respecto se señala que "se gastan fondos públicos en intervenciones de salud de escasa eficacia en función de los costos, como la cirugía en la mayoría de los casos de cáncer, al tiempo que sigue siendo insuficiente el financiamiento de otras medidas de importancia crítica y sumamente eficaces en función de los costos como el tratamiento de la tuberculosis y las enfermedades de transmisión sexual. Banco Mundial. óp. cit. pp. $3-4$.

42 Melero, Discusión en sala, Congreso Nacional. Óp. cit. 228
} 
políticas sociales ${ }^{43}$. Sin embargo, en esta parte del debate, también se puede apreciar que la relación de la derecha con las ideas propias del paradigma neoliberal es más compleja de lo que comúnmente se asume, porque no es una relación de aceptación total (como se critica fundamentalmente desde sectores de izquierda), ni tampoco es una relación de rechazo. Se aceptan ciertos elementos de manera casi completa, otros se aceptan con matices y otros se rechazan ocasionalmente. Así ocurre, como vimos con el principio de eficiencia que se acepta y se señala de forma reiterada, pero el rechazo al universalismo no opera con la misma fuerza, aunque sea un universalismo matizado y condicionado por las necesidades de focalización y el criterio de eficiencia.

Por otra parte, en lo que se refiere a la defensa de ciertos aspectos del modelo de salud impuesto en dictadura la Derecha hizo una defensa de los intereses de las ISAPRE y se negó a aprobar cualquier tipo de modificación que implicara tomar una mínima parte de los recursos de dichas instituciones. Esta defensa se produjo a raíz de las intenciones del gobierno de implantar un subsidio maternal, que se financiara con el $0,6 \%$ de las cotizaciones de los afiliados a ambos sistemas y la argumentación giró en torno al derecho a la propiedad privada y en torno a un tecnicismo respecto del uso de los impuestos y su recaudación. Respecto del primer tema el diputado Melero señaló que la intención de tomar parte de la cotización de las ISAPRES afectaba la propiedad:

En el sentido de que es el cotizante el dueño de su siete por ciento. No se puede, en virtud de una ley, conculcando las garantías constitucionales, afectar la propiedad privada que el cotizante tiene sobre su siete por ciento. Obligarlo a financiar de su bolsillo un adicional es una forma de expropiación sobre un derecho constitucional constituido por la propiedad del siete por ciento ${ }^{44}$.

Se puede advertir que se apela a que los cotizantes son los dueños del $7 \%$, pero nada se dice de que parte importante de ese $7 \%$ contribuye a generar las enormes ganancias del sistema de salud privado, de tal modo que se utiliza un argumento que soslaya el hecho de que la cotización de los usuarios de las ISAPRE, no se utiliza para otorgarles prestaciones de salud, sino que va a parar a las utilidades de las empresas. En este sentido se defiende una propiedad que está solo en el papel, para defender los intereses de los principales beneficiaros del sistema, es decir, las propias ISAPRE. El otro argumento utilizado para defender el modelo de salud se refiere a que la propuesta de tomar parte del 7\%, constituye un impuesto, lo que no implica en sí mismo un problema, pero si es problemático por el uso que se le pretende dar a dicho impuesto:

Si se obliga a las isapres a financiarlo, se cae en un segundo problema, porque pasa a constituir un impuesto con un fin específico para solventar el prenatal y el posnatal. Obviamente, el gravar con un impuesto, con un fin específico, el sistema de salud privada es inconstitucional, desde el punto de vista de generar un impuesto que tiene

\footnotetext{
43 Ver por ejemplo, Fontaine, J, “Transición económica y política en Chile: 1970-1990”. Estudios Públicos, n 50, 1993. Santiago, pp. 229 - 279.

44 Melero, Discusión en sala. Melero, Congreso Nacional. Óp. cit. 229.
} 
una finalidad específica, en circunstancias de que los impuestos globales de la Nación deben ingresar en las arcas fiscales y de allí ser distribuidos ${ }^{45}$.

Acá nos encontramos con un argumento técnico, respecto de si dicho cobro de un 0,6\% de la cotización es o no un impuesto, discusión que dividirá a los diputados, pero que más allá de la pulcritud jurídica, lo que nos interesa rescatar es que se utilizó dicho argumento para defender un componente central del sistema de salud impuesto durante la dictadura. En este sentido, la derecha demostró que su disposición para reformar el sistema de salud tenía un límite y ese límite estaba dado por la defensa de los intereses de las ISAPRE.

Creemos que dicha defensa se relaciona con uno de los rasgos distintivos de la derecha chilena que más que ser la defensora del ideario neoliberal, es la defensora de los intereses del gran empresariado. Esto también lo podemos apreciar cuando se aborda el tema de la compra de servicios por parte del sector público al sector privado, ya que, dicha argumentación se aleja de ciertos principios neoliberales, sobre la ineficiencia estatal y la limitación de la acción del Estado al subsidio solo a los más pobres, pero se mantiene la defensa del empresariado. Ello lo podemos apreciar en la siguiente intervención de Melero, quien valora la complementariedad público - privada:

A veces, hay una suerte de omnipotencia al pensar que es responsabilidad del Estado entregar toda la atención de salud...

Se debe buscar una complementación entre lo público y lo privado; de forma tal que cuando el sector público no pueda entregar un determinado servicio, lo compre al sector privado. Ello nada tiene de malo, sino que genera mucho de bueno respecto de la eficiencia...

En el país hay ejemplos interesantes; quizás, el más emblemático es el tratamiento de las insuficiencias renales: si mal no recuerdo, el sector público compra cerca del 80 por ciento de las diálisis al sector privado. Es una de las cosas que funcionan bien...

Avanzar aún más sin ideologismos exacerbados para aprovechar mejor la infraestructura que el país tiene y ser eficientes en la atención de la gente, que finalmente es lo que más importa, constituye un elemento sustancial de esta reforma ${ }^{46}$.

Nuevamente acá se puede apreciar que no se demoniza al Estado, en el sentido que no se dice que la salud debe mercantilizarse por completo, pero lo más interesante, a nuestro juicio, es que se habla de una complementariedad público - privada, donde el Estado, en su rol subsidiario, no debe entregar por completo un servicio a quienes no pueden pagar por él, sino que debe recurrir al mercado, pero subsidiando la oferta, con lo que se constituye otro ejemplo de mercantilización subsidiada que se presenta solo con efectos positivos, ya que permite a las personas satisfacer una necesidad y que gocen de la prestación de un derecho, pero además se crea un buen negocio para el sector privado.

La tónica de los argumentos señalados por el diputado Melero se mantuvo, en esta instancia, en lo expuesto por el diputado Masferrer, también de la UDI, ya que también

\footnotetext{
45 Melero, Discusión en sala, Congreso Nacional. Óp. cit.230.

${ }^{46}$ Melero, Discusión en sala. Congreso Nacional. Óp. cit. 230 - 231.
} 
valoró el avance que significaba el proyecto en términos de calidad, oportunidad y protección financiera ${ }^{47} \mathrm{y}$, asimismo, recalcó el avance que implicaba en materia de eficiencia en el plano sanitario. Al respecto señaló que:

Teniendo en cuenta que Chile es un país no de pocos recursos, sino de escasos recursos, parece positiva la idea de establecer un orden de prioridades de tratamiento de enfermedades. Si bien ello, en la práctica, va a significar una especie de discriminación en contra de los enfermos "no Auge", es un avance sustancial para el tratamiento de las enfermedades que más afectan a los chilenos ${ }^{48}$.

Como se ve, al igual que el diputado Melero, se recalca que, ante la escasez de recursos, se debe priorizar, aunque ello implique una cierta discriminación. Pero también agregó que la eficiencia no solo se debía plasmarse en la focalización de las enfermedades de mayor impacto, sino también en una reforma a la institucionalidad, porque de lo contrario podía continuar el "despilfarro de recursos en la misma forma que ha sucedido en la década de los años 90, en que se triplicó el presupuesto de la Salud e igualmente bajó el índice de eficiencia en las prestaciones efectivamente otorgadas" 49 . Nuevamente la salud es tratada como un producto.

Por otra parte, el diputado Masferrer, en sintonía con lo ya señalado por Melero, también cuestiona el polémico Fondo Maternal Solidario. Sin embargo este diputado, agregó otro argumento en el cuestionamiento de dicha iniciativa y señaló que la fórmula propuesta de financiamiento del Fondo encarecería los planes de salud de los afiliados a las ISAPRE50, aunque no se explaya mucho en explicar por qué ocurriría ello. Acá el diputado se presenta como defensor de los intereses de la ciudadanía, sin explicitar que, en el articulado respecto del Fondo, nada obligaba a las ISAPRE a subir el costo de los planes a sus afiliados.

Con este tipo de argumentos se buscaba defender los intereses de las ISAPRE de forma velada, apelando a los intereses de sus beneficiarios, ya que la defensa abierta, era blanco de críticas de parte de los diputados de la Concertación. En este punto es pertinente destacar que Masferrer, no se opuso a la existencia de un subsidio, sino que, a lo que se opuso, es a que dicho subsidio lo pagaran, en alguna medida, las ISAPRE, ya que se mostró partidario de mantener el subsidio maternal estatal ${ }^{51}$ que se dirigía, principalmente, a sectores de altos ingresos, lo que contradice el corazón mismo del principio de subsidiariedad. Pero además es posible advertir que, con el objetivo de defender los intereses del empresariado ligado a la salud, se sacrifican principios importantes del neoliberalismo, como el principio de eficiencia, puesto que los recursos no se gastan en quienes más lo necesitan, sino en sectores de mayores ingresos.

Otro de los elementos a destacar presentado por el diputado Masferrer, se refiere a retomar una indicación presentada en la Comisión de Salud referente a la posibilidad de

\footnotetext{
47 Masferrer, Discusión en Sala. Congreso Nacional. Óp. cit. 241.

48 Masferrer, Discusión en Sala. Congreso Nacional. Óp. cit. 242.

${ }^{49}$ Masferrer, Discusión en Sala. Congreso Nacional. Óp. cit. p 242.

50 Masferrer, Discusión en Sala. Congreso Nacional. Óp. cit. 243.

51 Masferrer, Discusión en Sala. Congreso Nacional. Óp. cit. 243.
} 
que los usuarios de FONASA, pudieran elegir atenderse en centros de salud privados si es que la red pública no pudiese hacerlo en los tiempos oportunos. Ello permitiría cumplir con una de las garantías explícitas y evitaría que las personas tuvieran que recurrir a los tribunales de justicia para exigir el cumplimiento de las garantías, agregando otro problema a los ya colapsados tribunales ${ }^{52}$.

Tenemos, con ello, nuevamente un ejemplo de mercantilización subsidiada, elemento que consideramos central en relación con la postura de la derecha frente a la acción económico - social del Estado, ya que aparece de forma reiterada, primero presentado como indicación en la comisión de salud, luego mencionado por el diputado Melero y ahora, nuevamente expresado por Masferrer.

Por otra parte, la diputada de la UDI María Angélica Cristi, presentó un par de argumentos novedosos respecto de los expuestos por sus pares de partido. En este sentido valoró la iniciativa, señalando incluso que "no puede haber chileno bienintencionado al que no le importe el bien común y su patria, que no desee que esta reforma sea un éxito"53. Aquí lo nuevo es la apelación directa al bien común, elemento no muy utilizado en general por la derecha, lo que se refleja, en que los diputados del sector que le antecedieron valoraron, principalmente, el avance que significaría el proyecto en términos de eficiencia. Pese a su valoración positiva planteó algunas aprensiones respecto del financiamiento de la reforma. $\mathrm{Al}$ respecto señaló lo siguiente:

Me preocupa cómo se financiará el Auge. Si bien hay un proyecto para ese efecto, siento que, hasta el momento, dicho plan no tiene un financiamiento viable. De hecho, en la Comisión de Salud algunos diputados ya manifestaron su aprensión por el establecimiento del impuesto al diesel, debido a que podría incidir en el aumento de la cesantía, en el incremento del costo de los transportes y por el impacto que podría tener en la pequeña y mediana empresa ${ }^{54}$.

Destacamos este párrafo porque refleja una defensa explícita del empresariado, aunque se recurra al argumento del posible aumento de la cesantía, tema sensible, aún en 2002, lo que representa, a nuestro juicio, una de las construcciones argumentativas más recurrentes de la derecha, ya que de manera reiterada se defienden los intereses del empresariado, pero apelando a los intereses de otros sectores sociales, en este caso a los intereses de los trabajadores en general, amenazados por la cesantía y a la defensa de los sectores medios, representados por los pequeños y medianos empresarios. Este último sector social aparece de manera reiterada en las argumentaciones de la derecha.

Sin embargo, en el punto que la diputada más se aleja de lo señalado por los otros diputados de su sector es en el referente a lo que ocurriría con los pacientes que padecían enfermedades no incluidas en el AUGE, ya que solo ella se refirió con detención a este problema. A este respecto señaló:

\footnotetext{
52 Masferrer, Discusión en Sala. Congreso Nacional. Óp. cit. 243 - 244.

53 María Angélica Cristi. Discusión en sala. Congreso Nacional. 249.

54 María Angélica Cristi. Discusión en sala. Congreso Nacional. 248.
} 
Si bien considero que estas garantías de atención están bien elegidas y son importantes, habrá pacientes de primera y de segunda, según las enfermedades que los afecten. Los de primera, sin duda, van a ser bien atendidos, con costos bien evaluados y se salvarán muchas vidas, aunque los expertos aseguran que no sobrepasarán el 40 por ciento. Sabemos, sin embargo, que sólo Dios puede determinar cuándo es posible resolver una enfermedad de riesgo, pero ése no es un punto de discusión en este tema. ¿Qué pasará con el resto de los chilenos que serán afectados por patologías que no están incluidas en el plan Auge, que, según las sociedades científicas, son más de ocho mil? ¿Cómo se va a sentir el día de mañana una persona que lleve a su marido o a su hijo con una cirrosis al hígado a un establecimiento hospitalario y le digan que esa patología no está considerada en el plan Auge y que, por lo tanto, debe esperar?55

Destacamos el párrafo anterior porque resulta diferente dentro de la argumentación general de la derecha, pero, fundamentalmente, porque expresa las mismas aprensiones que el diputado Sergio Aguiló, quien poseía posiciones claramente de izquierda ${ }^{56}$.

Lo anterior es llamativo, porque, en general, derecha e izquierda no suelen recurrir a los mismos argumentos y porque se aleja, en alguna medida, del argumento de la eficiencia y la escasez de recursos, el que, como vimos, fue un elemento destacado en la argumentación realizada por los diputados de Derecha que le precedieron. Tal vez sea este el único elemento disonante dentro de la argumentación general del sector estudiado. De hecho, el único diputado de Renovación Nacional que intervino, Carlos Kuschel no presentó nuevos argumentos y de su intervención solo consideramos relevante destacar su desacuerdo con el impuesto al Diesel, reforzando la idea ya expuesta por la diputada Cristi, pero centrándose en el impacto negativo que tendría en su región. Al respecto señaló lo siguiente:

El incremento de dicho impuesto afectará directamente a las regiones. Hay que recordar que hemos suscrito acuerdos de libre comercio muy importantes y que es necesario tener altos niveles de competitividad, y nuestra región tiene un alto consumo de combustibles, especialmente de petróleo Diesel, debido a su actividad salmonera, pesquera en general, agrícola y de transporte de carga y pasajeros ${ }^{57}$.

Como se puede apreciar el problema del financiamiento sigue apareciendo como prioritario y respecto de él se presentan argumentos orientados a defender la actividad del empresariado privado, aunque en este caso no se recurre al argumento de la defensa de otros sectores sociales. Aun considerando las aprensiones y dudas presentadas, no solo por la derecha, lo cierto es que en esta instancia el proyecto concitó apoyos transversales y, de hecho, fue aprobado casi por unanimidad, con cero votos en contra y con la sola abstención

\footnotetext{
55 María Angélica Cristi. Discusión en sala. Congreso Nacional. 247.

56 Sus posiciones a la izquierda del espectro político chileno quedan bien reflejadas en su carrera política, ya que fue militante de la Izquierda Cristiana, elegido diputado en 1989 en un pacto que incluía al Partido Comunista, y aunque ingresó al Partido Socialista en 1990 emigró del mismo en 2011 para concurrir a la formación de partidos de izquierda que hicieron alianzas con el PC, hasta esa fecha aún excluido de la alianza concertacionista. 57 Carlos Kuschel. Discusión en sala. Congreso Nacional. 260.
} 
de la diputada Lily Pérez de Renovación Nacional ${ }^{58}$. Pese a tal consenso, de todas formas, se hicieron algunas indicaciones al proyecto, las que debían volver a discutirse en las comisiones pertinentes, pero en solo una de ellas aparecen diputados de derecha. En concreto los diputados Forni, Masferrer y Melero, todos de la UDI, junto a los diputados Aguiló (PS) y Cornejo (DC) hicieron una indicación tendiente a permitir que los usuarios de FONASA pudieran atenderse en centros de salud privados, si la red pública no lo hacía en el tiempo oportuno. La indicación señalaba lo siguiente:

En caso de que el plazo indicado en el inciso primero expire sin que la respectiva prestación haya sido otorgada, no obstante haber sido solicitada por el beneficiario, éste podrá concurrir a cualquier profesional o establecimiento de salud que tenga convenio con el Fondo Nacional de Salud...

Si el copago que deba realizar el beneficiario... fuese inferior al que correspondería hacer conforme al convenio celebrado entre el profesional o establecimiento de salud respectivo y el Fondo Nacional de Salud, la diferencia será de cargo de éste, y deberá ser enterada al profesional o establecimiento de salud ante la sola presentación del documento, el que tendrá, para todos los efectos legales, el carácter de título ejecutivo en contra del Fondo Nacional de Salud. ${ }^{59}$.

Nuevamente se vuelve a insistir en esta idea que asegura a las empresas privadas de la salud poder lucrar por sus servicios, aún con pacientes de menores ingresos.

\subsection{Fase final. Discusión en las comisiones de hacienda y salud y última discusión en la sala.}

En la sesión de la Comisión de Salud, celebrada el 14 de enero de 2003, la Diputada Cristi y los Diputados Forni, Masferrer y Melero (todos UDI) volvieron a insistir en la misma idea del bono para que los usuarios de FONASA pudieran acceder al sistema privado, de no obtener atención oportuna en la red pública, al formular, por cuarta vez, la misma indicación ${ }^{60}$, con lo que se pone de manifiesto la centralidad que tenía dicha propuesta, para el sector político estudiado.

Otro punto relevante de la discusión en la sesión mencionada, se refiere a que el ejecutivo, a través de una indicación, repuso el sentido original del Fondo de Compensación Solidario, en lo referente a que fuera un fondo entre las ISAPRE y FONASA, lo que permitiría atraer "recursos desde las Instituciones de Salud Previsional al Fondo Nacional de Salud"61. La derecha rechazó la indicación, pero fue aprobada igual y así quedó en el proyecto presentado por la Comisión de Salud, con lo que su discusión se trasladó a las instancias siguientes.

El mismo 14 de enero de 2003 se reunió la Comisión de Hacienda. En ella los diputados Dittborn y Von Mühlenbrock (ambos UDI), formularon una indicación para

\footnotetext{
58 Votación en sala. Congreso Nacional. 264.

59 Indicación presentada en la sala. Congreso Nacional. 265.

$602^{\circ}$ Informe Comisión de Salud de la Cámara de Diputados. Congreso Nacional. 284.

$612^{\circ}$ Informe Comisión de Salud de la Cámara de Diputados. Congreso Nacional. 295 - 296.
} 
suprimir un artículo que señalaba explícitamente que el aporte fiscal destinado a asegurar las garantías de los usuarios de FONASA que no se cotizaran, no podría, en ningún caso, traspasarse "desde el Fondo Nacional de Salud, o desde sus afiliados, hacia las Instituciones de Salud Previsional o a sus afiliados" 62 .

En esta propuesta se puede apreciar, nuevamente, que no se cuestiona la idea de que el Estado gaste en prestaciones sociales, pero si se cuestiona que dichos recursos no puedan llegar al sector privado, es decir, no se ponen reparos a un incremento en el gasto público si es que éste puede llegar a la empresa privada. Como dicha indicación fue rechazada, entonces la Derecha votó en contra de todo el artículo, que, de todas formas, fue aprobado por la mayoría concertacionista63.

Respecto del polémico Fondo de Compensación Solidario, los 5 diputados de derecha presentes en la Comisión de Hacienda ${ }^{64}$, a diferencia de lo ocurrido en la Comisión de Salud, no se opusieron a la idea central del Fondo, esto es, compensar a FONASA por asumir beneficiarios de mayores riesgos, de tal modo que puesto en votación el artículo 24, que señalaba como se financiaría el Fondo, fue aprobado por la unanimidad de los diputados presentes 65 . Sin embargo sí rechazaron el artículo 26 que señala que "ninguna forma de funcionamiento del Fondo de Compensación Solidario podrá contemplar el traspaso neto de recursos desde el Fondo Nacional de Salud, o desde sus afiliados, hacia las instituciones de Salud Previsional, o hacia sus afiliados" 66.

Nuevamente es posible advertir que la derecha es partidaria del traspaso de recursos públicos hacia el sector privado, lo que está en contradicción con las visiones que afirman que la derecha es partidaria de limitar la acción estatal, ya que como vemos, en todas las instancias, se opone a que el Estado limite sus prestaciones solo a los beneficiarios de los servicios públicos y aboga por un traspaso de los recursos públicos hacia el sector privado, con lo que se configura una visión de la relación público - privada que no ha sido, a nuestro juicio, suficientemente destacada por los estudios existentes sobre la Derecha.

Dado que, en las comisiones, la Derecha no pudo imponer sus rechazos a ciertos artículos, la discusión se trasladó a la sala de la Cámara de Diputados que en sesión del 15 de enero de 2003 discutió por última vez el proyecto. En dicha instancia la Derecha rechazó en bloque las prohibiciones de transferencias de FONASA a las ISAPRE, establecidas respecto del Fondo de Compensación Solidario (artículo 26) y del subsidio estatal a los usuarios del primer tramo de FONASA (artículo 17). Asimismo, rechazó el mecanismo de financiamiento del Fondo Maternal Solidario y volvió a insistir en que los usuarios de FONASA pudieran atenderse en el sistema privado. Respecto del primer tema el diputado Julio Dittborn señaló lo siguiente:

Señora Presidenta, en este breve tiempo sólo me referiré al artículo 26 del proyecto que nos ocupa, y quiero pedir el pronunciamiento de la Mesa sobre su admisibilidad. A mi

\footnotetext{
$622^{\circ}$ Informe Comisión de hacienda de la Cámara de Diputados. Congreso Nacional. 374.

63 Ibíd., p 348.

64 Por la UDI: Julio Dittborn, Claudio Alvarado y Gastón Von Mühlenbrock. Por RN: Mario Bertolino y Carlos Hidalgo. Congreso Nacional. 351

$652^{\circ}$ Informe Comisión de hacienda de la Cámara de Diputados. Congreso Nacional. 348.

$662^{\circ}$ Informe Comisión de hacienda de la Cámara de Diputados. Congreso Nacional. 349
} 
juicio, es una materia que incide en la administración financiera del Estado. Como me parece que no se apega a la Constitución Política, hago reserva sobre su constitucionalidad.

Este artículo termina con el concepto del fondo de compensación al impedir el traspaso de recursos del sistema público al sistema privado, cuando haya personas de alto riesgo que elijan libremente el sistema privado. El Fondo de Compensación es, básicamente, solidario, y establece una prima universal única para la población de mayor riesgo, fundamentalmente según sexo y edad, la cual recibirá un subsidio del resto de los chilenos. Lo que hace el artículo 26 es impedir, cuando una persona de alto riesgo decide libremente cambiarse al sistema privado porque considera que le ofrece una atención de mayor calidad, que los recursos que legítimamente le corresponden vayan a ese sistema que eligió. Es decir, destruye el concepto de fondo de compensación único y, por lo tanto, el concepto más importante del plan Auge. De manera que es discriminatorio con las personas de alto riesgo que -repito- optan libremente por el sistema privado. En realidad, lo que hace este artículo es transformar el sistema privado de salud en elitista, al cual nunca podrán acceder las personas de más alto riesgo. Por lo tanto, anuncio nuestro voto en contra de este artículo, y solicito el pronunciamiento de la Mesa sobre su constitucionalidad ${ }^{67}$.

Transcribimos integra su intervención, porque refleja de manera clara y resumida, tanto los principios que defiende la derecha, como las estrategias argumentativas de este sector. En dicha cita se puede apreciar que para la derecha problema principal lo constituye la prohibición de que se traspasen recursos estatales a las empresas privadas de la salud, pero la argumentación no menciona en momento alguno a las ISAPRE, sino que se recurre a un principio fundamental del neoliberalismo, como lo es la libertad de elección, que dicho Fondo coartaría y además se apela a la defensa de las personas de menores ingresos que, de aprobarse el Fondo, no podrían optar por la salud privada y, por último, se recurre a la amenaza de cuestionar la constitucionalidad del artículo en discusión. Todo lo anterior nos permite advertir que para la derecha el rol del Estado, no solo es subsidiar a quienes quedan fuera del mercado, sino también la ganancia de la gran empresa privada. Además, la reserva de constitucionalidad muestra la decisión del sector en su defensa de las ISAPRE.

Lo anterior también se puede advertir en la intervención del diputado Francisco Bayó de RN, quien, recurriendo al argumento de la libertad de elección, criticó los artículos referentes a las prohibiciones antes mencionadas:

A mi juicio, no existe verdadera libertad de elección si cada chileno, pobre o rico, no tiene la posibilidad de elegir no sólo el sistema o subsistema público o privado en el cual decida atenderse, sino que también el profesional y el lugar de atención. Ésa es una verdadera libertad de elección, y a eso debemos apuntar. Lamentablemente los artículos 17 y 26 de este proyecto, que hoy analizamos en segundo trámite reglamentario, prácticamente, le ponen una lápida a la posibilidad de portar el subsidio... Pues bien, los artículos mencionados lo impiden y, por consiguiente, implican un atentado a la verdadera libertad de elección ${ }^{68}$.

67 Julio Dittborn. $2^{\circ}$ Discusión en Sala. Congreso Nacional. 375

68 Francisco Bayó. $2^{\circ}$ discusión en Sala. Congreso Nacional. p 378. 
En ambas citas queda de manifiesto que el problema central para la Derecha es que la prohibición de traspasar fondos públicos al sector privado, podría implicar que parte de los usuarios del sistema privado pudieran cambiarse al sistema público ${ }^{69}$. Ante esta posibilidad la derecha no afirma "que gane al más eficiente", o que "los que no pueden participar en el mercado está bien que se vayan al sector público" sino que dice: "los beneficios deben ser para los usuarios de ambos sistemas, porque si no se niega el principio de la libertad de elección", pero no dicen nada con respecto a que, si el beneficio se extiende a los usuarios de ambos sistemas, entonces también se está subsidiando a empresas privadas y con ello también se niega el principio de la no intervención estatal en el mercado, es decir, se utiliza un principio de neoliberal para defender los intereses del empresariado, aunque ello implique negar otro principio del neoliberalismo.

De todos modos, es relevante destacar que no hay un rechazo frontal a la idea del Fondo de Compensación Solidario. Esto implica que en un primer momento la derecha aceptó que las ISAPRE concurrieran con sus recursos a aportar en un fondo común que, por las características de riesgo de los usuarios de cada sistema, sería usado preferentemente por los usuarios de FONASA y solo cuestionaron que los fondos que aportaba FONASA, no pudieran llegara a los usuarios de las ISAPRES. Respecto del bono destinado a que los usuarios de FONASA se atendieran en el sistema privado si es que se excedían los tiempos de espera en el sistema público, fue el diputado Forni (UDI) quien insistió nuevamente en el tema:

Resulta preocupante que el proyecto del Ejecutivo no contenga ninguna norma que permita a los chilenos hacer efectivas esas garantías, situación que, inevitablemente, conducirá a judicializar el Auge...

Por eso, en conjunto con parlamentarios de la Concertación presentamos una indicación para agregar un artículo 14 bis, nuevo, que establecía algo muy sencillo: un bono automático, de manera que la persona que no sea atendida en la oportunidad o con la calidad que el proyecto garantiza, con la sola emisión de ese bono pueda recurrir a otro prestador -obviamente, que forme parte de la red o que tenga convenio- para hacer efectiva la garantía.

Lamentablemente, la incorporación de este bono - hace algunos meses se lo planteamos personalmente con el diputado Masferrer al ministro de Salud - quedó sólo en una buena idea, porque la indicación fue declarada inadmisible ${ }^{70}$.

Luego, la diputada María Angélica Cristi y el diputado Gonzalo Ibáñez, volverían a insistir en dicha idea y para ello argumentaron que el sistema público no tendría capacidad para atender las patologías AUGE. En concreto la diputada señaló lo siguiente:

\footnotetext{
69 Según los datos manejados por el Ministerio de Salud, en abril del 2004, de aprobarse el Fondo entre 67 mil y 83 mil personas deberían migrar del sistema privado al sistema público de salud, lo que representaba entre 2,5 y el $3 \%$ de los afiliados a las ISAPRE. El Mostrador, 8 de abril de 2004. http://www.elmostrador.cl/noticias/pais/2004/04/08/mas-de-80-mil-personas-migraran-de-isapres-afonasa-por-el-plan-auge/

70Marcelo Forni, $2^{\circ}$ discusión en Sala. Congreso Nacional. 380.
} 
Todos sabemos que muchos establecimientos asistenciales no van a tener las posibilidades de atender enfermedades consideradas en el plan Auge y a ellos concurren especialmente las personas más pobres...

Me preocupa lo que he planteado hasta el cansancio: que los establecimientos del sector público no van a estar preparados para hacer efectivo el plan Auge y el proyecto no resolverá el problema ${ }^{71}$.

Acá la justificación del bono, no se basa en la intención de evitar la judicialización en la atención de salud, sino que en la discriminación que se produciría con los sectores más pobres que no podrían disfrutar de las garantías explícitas. Este argumento constituye un ejemplo más de lo señalado más arriba, respecto de que la derecha, en su defensa de los intereses del empresariado, se presenta como la defensora de otros sectores sociales, en este caso, de los más pobres.

El hecho de que se vuelva a insistir en el mismo tema, pese a que ya se había establecido que solo el ejecutivo podía propiciar dicha indicación, demuestra lo importante que era esta propuesta, que creaba con fondos estatales un nuevo negocio para el sector privado, apelando a una especie de subsidiariedad invertida", en el sentido de que se afirma que, dada la precariedad del Estado, entonces se debe recurrir a los privados, pero asegurándoles a estos la ganancia.

Finalmente, el último punto problemático se refería a la utilización del 0,6\% de la cotización de los beneficiarios de ambos sistemas para financiar el Fondo Maternal Solidario. Al respecto se refirió el diputado Rodrigo Álvarez, también de la UDI:

Mi intervención se limitará a anunciar la reserva de constitucionalidad respecto del artículo 30, en especial en cuanto a la composición de uno de los aportes al fondo maternal solidario. En este caso, se trata de un ingreso de carácter público o tributo que, además, se cobra sin entregar ningún tipo de prestación correlativa y hecho efectivo de manera indirecta a través de la isapre, lo que afecta directamente a los cotizantes del sistema.

Por esa razón y porque el precepto vulnera disposiciones claras en materia constitucional tributaria, en nombre de mi bancada anuncio reserva de constitucionalidad respecto de los artículos 30 y siguientes, en lo relativo a la forma financiera establecida por la iniciativa en la composición del Fondo Maternal Solidario ${ }^{72}$.

La negativa de la UDI a aprobar dicho artículo fue respondida por Guido Girardi, quien en su intervención mostró las inequidades del subsidio maternal estatal vigente y que el Fondo Maternal Solidario buscaba reemplazar:

No puede ser que en Chile se entreguen 60 mil millones de pesos a los sectores de más altos ingresos. En los otros subsidios, normalmente, el 73 por ciento va al 40 por ciento de la población más pobre, pero cuando se trata del subsidio maternal, lamentablemente, sólo el 9 por ciento de los recursos va al 40 por ciento de los más pobre. ¿Qué quiere decir eso? Que el 80 por ciento de los recursos del subsidio maternal -60 mil

\footnotetext{
71 María Angélica Cristi, Discusión en sala, Congreso Nacional. 388.

72 Rodrigo Álvarez, Discusión en sala. Congreso Nacional. 384.
} 
millones de pesos- va al 40 por ciento más rico del país y el otro 20 por ciento al 60 por ciento de todos los chilenos. ¿Por qué el 20 por ciento para el 60 por ciento más pobre y el 80 por ciento para el 20 por ciento más rico? Ésas son las contradicciones que un sector del país, que dice que le interesa la pobreza y la equidad, tiene que responder y aclarar ${ }^{73}$.

La interpelación que realizó Girardi, es interesante porque remarca el hecho de que, pese a la pretendida defensa de la derecha de los sectores medios y bajos, lo cierto es que, respecto de este Fondo, lo que hace la derecha es defender los intereses de los sectores de mayores ingresos, al punto de hacer una reserva de constitucionalidad, lo que, a su vez, muestra los límites que la derecha consideraba infranqueables en su defensa del modelo. En este sentido es ilustrativo comparar la acción de este sector político respecto del Fondo de Compensación Solidario y del Fondo Maternal Solidario. Ello porque el primero se financiaba con una prima universal equivalente para ambos sistemas, por lo que, en montos absolutos, la mayor parte del Fondo la conformarían recursos provenientes de FONASA que tiene una mayor cantidad de afiliados, aunque por la distinta composición del riesgo de los mismos, una parte de los recursos irían desde el sector privado al público. Como vimos la derecha no se opuso a dicha idea. En cambio, fue muy distinta su reacción frente al segundo Fondo mencionado, porque este establecía una cotización proporcional a la cotización, no un monto fijo, es decir, quienes cotizaran más, aportarían más. De este modo las ISAPRE que recaudan las cotizaciones de trabajadores de mayores ingresos y en su mayoría hombres, aportarían con mayores recursos al Fondo, que sería mayormente utilizado por mujeres de menores ingresos pertenecientes a FONASA. Ante este escenario, la derecha se opuso de manera frontal y muestra que la defensa de los beneficios de las ISAPRE, constituye un elemento intransable del sistema y por ello, prefería mantener, tal como lo señaló el diputado Melero ${ }^{74}$, un subsidio estatal que se dirigía a los sectores más ricos de la población, contradiciendo, con ello, la esencia misma del principio de subsidiariedad 75 .

\section{Conclusiones.}

De la revisión de la discusión sobre la reforma de la salud, podemos extraer varias conclusiones importantes. En primer lugar, podemos apreciar que no hay diferencias sustantivas entre los diputados de la Derecha, de tal modo que las argumentaciones de los diputados UDI y RN son completamente equivalentes. En este contexto, la única voz parcialmente disonante la expresó María Angélica Cristi, puesto que manifestó sus aprensiones respecto de lo que ocurriría con los pacientes con patologías no AUGE, desalineándose de la posición general de su sector que valoraba la eficiencia que implicaba priorizar solo las patologías de mayor impacto.

73 Guido Girardi, Discusión en sala. Congreso Nacional. 387.

74 Patricio Melero, Discusión en sala. Congreso nacional. 393.

75 Y también contradiciendo, como vimos, las sugerencias del Banco Mundial, respecto de focalizarse en los más pobres. 
En relación con los roles asignados al Estado se puede advertir que la Derecha le asigna al Estado un rol importante en materia de protección social, aunque dicho rol debe subordinarse al principio de eficiencia en el manejo de los recursos, idea que si, está muy acorde con el ideario neoliberal.

Además al Estado se le asigna un rol subsidiario, pero, como vimos, no solo en el sentido neoliberal de subsidiar a quienes no pueden participar en el mercado, sino, fundamentalmente, en el sentido de subsidiar la ganancia privada, incluso de grandes empresas, a través del mecanismos de traspasar fondos públicos a entes privados para otorgar prestaciones a quienes no pueden participar en el mercado, lo que hemos designado con los conceptos de subsidiariedad invertida (como el Estado no es capaz de otorgar una prestación, entonces deben hacerlo los privados) y mercantilización subsidiada (el Estado asegura a los privados una ganancia por atender a los beneficiarios del sistema público).

Aunque estas ideas no sean explícitamente asumidas por la derecha, lo cierto es que la insistencia en que los usuarios de FONASA pudiesen atenderse en el sistema privado y el rechazo a prohibir el traspaso de fondos públicos al sector privado, muestran que la derecha es una firme defensora de los subsidios estatales al empresariado privado. Lo anterior implica una valoración positiva de la complementariedad pública - privada que se aleja de la "demonización" de la acción estatal, tan propia de los autores de la escuela de Chicago.

Por otra parte, se le niega al Estado un rol redistributivo, lo que se refleja en su rechazo al mecanismo de financiamiento del Fondo Maternal Solidario que buscaba utilizar los recursos de los sectores más ricos para financiar los subsidios maternales de los grupos más vulnerables. Esto se relaciona con aquello que la derecha considera intocable del modelo económico y social heredado de la dictadura. A nuestro juicio, en el ámbito de la salud, esto está representado por la defensa de las ISAPRE, ya que la derecha estuvo dispuesta a regular el negocio e incluso a incluir algunos elementos de solidaridad, pero no estuvo disponible para concurrir con sus votos a aprobar medidas que utilizaran los fondos administrados por las ISAPRE para ser redistribuidos entre grupos de menores ingresos, con lo que se puede advertir un rasgo de continuidad con la derecha anterior al "giro neoliberal" que, al igual que la derecha del periodo estudiado, es una firme defensora de los intereses de los grupos propietarios del país y, para asegurar dicha defensa, se mostró partidaria de mantener un subsidio estatal destinado a sectores de altos ingresos, contraviniendo, con ello, las ideas de focalización, eficacia y eficiencia.

Esta postura de la derecha frente a la acción estatal, podría pesquisarse al estudiar la respuesta de este sector frente a otros proyectos de reforma, como lo fueron la creación de los Créditos con Aval del Estado, la reforma de pensiones, diversas reformas laborales, etc. para evaluar si también se presentan argumentos que se alejan del neoliberalismo, con el objeto de defender los intereses del empresariado.

Cabe destacar que este matiz de la derecha, respecto del neoliberalismo hacia posiciones más flexibles y pragmáticas, se relacionan, según Rovira, con necesidades electorales, de adaptarse a las demandas de la ciudadanía y con la capacidad de nuevos actores políticos de politizar la desigualdad y legitimar propuestas opuestas al modelo neoliberal76, pero a nuestro juicio este cambio, también puede asociarse con la no amenaza

${ }^{76}$ Rovira, C. “La (sobre) adaptación programática de la derecha chilena. 2019. En proceso de publicación. 
real al modelo, por parte de la acción estatal, es decir, puesto que el Estado ya no representa una amenaza para la propiedad privada, entonces la derecha está dispuesta a revalorar su intervención y su actuación se avoca a evitar las rectificaciones redistributivas y a buscar nuevas fuentes de negocios para el empresariado ${ }^{77}$.

En este sentido, estimamos que la derecha recurre al discurso antiestatista neoliberal, cuando la acción estatal representa una amenaza para los intereses del empresariado privado, pero si ello no es así, puede hacerse más flexible y pragmática. En este sentido podría entenderse la actitud de la derecha frente a las reformas impulsadas durante el segundo gobierno de Bachelet (proyectos de reforma tributaria, educacional y laboral), ya que al ver atacados los intereses del empresariado la derecha volvió a reaccionar con el discurso liberal anti estatista.

Por último consideramos relevante destacar que, ante la consolidación del modelo socioeconómico, la derecha volvió a carecer de proyecto específico y ha vuelto a ser racionaría, tal como lo fue hasta $\operatorname{los} 60^{78} \mathrm{y}$, nuevamente, se limita a maniobrar para evitar los afanes redistributivos que puedan afectar a los grupos propietarios del país. En dicha tarea cuenta con los enclaves autoritarios que le permiten frenar los intentos de cambio. Ante ello la derecha dejó de "pensar" y de preocuparse por construir una hegemonía ideológica y un proyecto de país ${ }^{79}$ y, en gran medida, en el discurso público y en sus documentos oficiales, continua repitiendo lo que Laval y Dardot denominan una vulgata de exacerbación del mercado y denostación del Estado ${ }^{80}$, aunque ello ya no refleje su accionar político concreto. Este pragmatismo y abandono de lo ideológico podría encontrarse en la base del surgimiento de discursos de extrema derecha que abogan por reponer un ideario más "puro" en temas económicos, sociales y valóricos, aunque aún es muy pronto para determinar si estas posturas lograran hacer mella en el grueso de la derecha post-dictadura que, tal como su predecesora anterior a la debacle de 1965, mantuvo posturas flexibles y pragmáticas para defender los intereses de los grupos propietarios del país.

\section{Bibliografía}

\footnotetext{
77 El funcionamiento del plan AUGE se constituyó en otra fuente de ingresos para los empresarios privados de la salud, en especial para las ISAPRE, las que aumentaron significativamnete sus utilidades desde la puesta en marcha del plan. Ello porque los cobros que dichas instituciones realizan a sus cotizantes para asegurar el financiamiento del Plan, han superado largamente los gastos que han debido hacer para asegurar el tratamiento de una patología AUGE.

Así, durante los diez primeros años del AUGE (2005 - 2015), los ingresos que percibieron las ISAPRES por este concepto fueron US\$2.090 millones (\$ 1.264 .301 millones), mientras que los gastos ascendieron a US\$ 1.118 millones (\$ 676.187 millones), es decir un 53\% de los ingresos. De este modo el margen operacional de la industria asciende a US\$ 900 millones o \$544.385 millones. Estos ingresos, obviamente, han aportado en las importantes ganancias de la industria, tal como lo reconoció en su momento el superintendente de salud cuando afirmó que: "no podemos obviar que esto ha significado una nueva fuente de ingresos para las Isapres". Diario Financiero, 15/06/2015.

http://www.nexchannel.cl/Nex/noticias/ver_imagen.php?img=2015/06/15/ElDiarioFinanciero-10

78 Bohoslavsky, E .óp. cit.

${ }^{79}$ Mansuy, D. Nos fuimos quedando en silencio. Santiago. Instituto de Estudios de la Sociedad. 2016.

80 Laval y Dardot. Óp. cit. pp. 208 - 210.
} 
1. Allamand. A. La centroderecha del futuro. Editorial Los Andes. Santiago, 1993

2. Banco Mundial. Informe sobre el desarrollo Mundial 1993. Invertir en salud. http://documentos.bancomundial.org/curated/es/282171468174893388/Informe-sobreel-desarrollo-mundial-1993-investir-en-salud.

3. Bohoslavsky, E. “¿Qué es lo nuevo de la nueva derecha en Chile? Anticomunismo, corporativismo y neoliberalismo, 1964-1973". História Unisinos. Vol. 16, n²1, 2012. pp. 5-14. http://revistas.unisinos.br/index.php/historia/article/view/htu.2012.161.01

4. Corra, Correa, S. Con las riendas del poder. La derecha chilena en el siglo XX. Santiago. Ed. Sudamericana. 2004.

5. Coto, J. Resumen del texto Libertad de elegir de Milton y Rose Friedman. www.unavisioreformista.wordpress.com.

6. Fontaine, J, “Transición económica y política en Chile: 1970-1990”. Estudios Públicos, n 50, 1993. Santiago, pp. $229-279$.

7. Friedman, M. “Bases para un desarrollo económico". Conferencia ofrecida por el Dr. Milton Friedman en el Edificio Diego Portales de Santiago, el 26 de marzo de 1975. En Soto, A (comp). Un legado de libertad. Milton Friedman en Chile. Instituto Democracia y Mercado/Atlas Economic Research Foundation/ Fundación para el Progreso. Santiago, 2012

8. Garretón, M. Neoliberalismo corregido; Editorial ARCIS-CLACSO-PROSPAL, Santiago, 2012

9. Judt, T. Algo va mal. Madrid. Taurus, 2010.

10. Laval y Dardot. La Nueva Razón del Mundo. Barcelona. Gedisa, 2013.

11. Mansuy, D. Nos fuimos quedando en silencio. Santiago. Instituto de Estudios de la Sociedad. 2016.

12. Morresi, S. La nueva derecha argentina, la democracia sin politica. Universidad Nacional General Sarmiento-Biblioteca Nacional, Buenos Aires, 2008

13. Piketty, T. El capital en el siglo XXI. México, FCE, 2015.

14. Rovira, C. “La (sobre) adaptación programática de la derecha chilena. 2019. En proceso de publicación. 
15. Saad-Filho, A y Johnston, D. Neoliberalism. A critical reader. Pluto Press, Londres, 2005

16. Taylor, M. From Pinochet to the third way. Pluto Press, London, 2006

\section{Fuentes}

Historia de la Ley $\mathrm{N}^{\mathrm{o}}$ 19.966. Establece un régimen de garantías de salud. Biblioteca del Congreso Nacional de Chile, 2004.

https://www.bcn.cl/historiadelaley/nc/historia-de-la-ley/5682/

Diario Financiero, 15 de Junio de 2015.

http://www.nexchannel.cl/Nex/noticias/ver_imagen.php?img=2015/06/15/ElDiarioFin anciero-10

El Mostrador, 8 de abril de 2004.

http://www.elmostrador.cl/noticias/pais/2004/04/08/mas-de-80-mil-personasmigraran-de-isapres-a-fonasa-por-el-plan-auge/

Declaración de Principios Unión demócrata Independiente (UDI). Disponible en:

http://www.udisantiago.cl/documentos/dec_princip.pdf 